\title{
Efficacy and safety of DFN-15, an oral liquid formulation of celecoxib, in adults with migraine: a multicenter, randomized, placebo-controlled, double-blind, crossover study
}

\author{
This article was published in the following Dove Press journal: \\ Neuropsychiatric Disease and Treatment \\ 7 November 2017 \\ Number of times this article has been viewed
}

\author{
Sagar Munjal \\ Alix Bennett \\ Promius Pharma, Princeton, NJ, USA
}

\begin{abstract}
Background: The objective of this proof-of-concept study was to assess the safety, efficacy, and potential for dose response of a new oral liquid formulation of celecoxib, DFN-15, in adults with migraine. Variability in patient-identified most bothersome symptom (MBS) across 3 migraine attacks was also evaluated.

Methods: This was a randomized, placebo-controlled, double-blind, 3-treatment, 6-sequence, 3-period, crossover study of 3 treatments (DFN-15 $120 \mathrm{mg}$, DFN-15 $240 \mathrm{mg}$, and placebo) administered at the onset of moderate to severe headache.

Results: Of 63 randomized subjects, 56 (89\%) took single doses of DFN-15 $120 \mathrm{mg}$ and $240 \mathrm{mg}$ and completed all 3 treatment periods. Most subjects were female (75.0\%) and white (86.7\%), with a mean age of 43.6 years. Both doses of DFN-15 achieved a higher 2-hour painfree response than placebo ( $29.1 \%$ for $120 \mathrm{mg}, 26.1 \%$ for $240 \mathrm{mg}$, and $17.6 \%$ for placebo), but the differences were not statistically significant. Photophobia was most commonly reported as the MBS, but for $53 \%$ of subjects (27/51), their identified MBS varied across the 3 studied attacks. The most common treatment-emergent adverse events with DFN-15 were dysgeusia $(\leq 11.8 \%)$ and nausea $(\leq 5.9 \%)$.

Conclusion: Both doses of DFN-15 outperformed placebo for the 2-hour pain-free end point, but due to a carryover effect with placebo, the differences were not statistically significant. Since response to both doses was similar, DFN-15 $120 \mathrm{mg}$ is being further developed for the management of acute migraine. Further study is needed to determine whether the current findings are altered by larger or different trial designs (ClinicalTrials.gov identifier: NCT02472418).
\end{abstract}

Keywords: episodic migraine, acute treatment, efficacy, safety, celecoxib

\section{Introduction}

Nonsteroidal anti-inflammatory drugs (NSAIDs) have been recommended for the treatment of episodic migraine, ${ }^{1,2}$ but cyclo-oxygenase (COX)-2 selective NSAIDs may provide a therapeutic advantage over nonselective NSAIDs due to a reduced risk of gastrointestinal (GI) adverse events (AEs), including upper GI ulcers and bleeds. ${ }^{3-5}$ Celecoxib is a selective COX-2 inhibitor that has shown analgesic effects similar to other NSAIDs. ${ }^{4}$ In the US, celecoxib is supplied as an oral capsule in several dosages (Celebrex ${ }^{\circledR}$; Pfizer Inc., New York, NY, USA), and it is indicated for the treatment of patients with osteoarthritis, rheumatoid arthritis, ankylosing spondylitis, acute pain, and primary dysmenorrhea. ${ }^{6}$ For the treatment of acute migraine, oral celecoxib was
Correspondence: Sagar Munjal Promius Pharma, 107 College Road East, Princeton, NJ 08540, USA

Tel +l 6093759083

Email smunjal@drreddys.com 
assessed in an open-label study comparing $400 \mathrm{mg}$ celecoxib oral capsules with naproxen sodium $550 \mathrm{mg}$ (Synflex ${ }^{\circledR}$; F. Hoffmann-La Roche Ltd), which reported that celecoxib caused significantly less gastric pain and is as effective as naproxen sodium. ${ }^{7}$

DFN-15 (Promius Pharma, Princeton, NJ, USA) is a new oral liquid formulation of celecoxib intended for the acute treatment of adults with episodic migraine. A recent pharmacokinetic (PK) study comparing DFN-15 with celecoxib oral capsules (400 mg) found that DFN-15 doses of $120 \mathrm{mg}$, $180 \mathrm{mg}$, and $240 \mathrm{mg}$ achieved substantially higher plasma concentrations of celecoxib (1062-1933 vs $611 \mathrm{ng} / \mathrm{mL})$ and faster median time to peak concentration ( 1 hour vs 2.5 hours). ${ }^{8} \mathrm{~A}$ new COX-2 inhibitor that is effective and more rapidly absorbed than nonselective NSAIDs could provide clinical benefits in migraine by achieving a rapid onset of action, which patients rank among the most important attributes of acute medication, ${ }^{9}$ and preventing the development of central sensitization, which decreases the likelihood of a successful outcome. ${ }^{10}$ Doses of $120 \mathrm{mg}$ and $240 \mathrm{mg}$ are currently in development, and a fully powered study is underway to assess their efficacy and safety in adults with episodic migraine (ClinicalTrials.gov identifier: NCT03009019). This small, preliminary study (ClinicalTrials. gov identifier: NCT02472418) was conducted to assess the safety and efficacy of DFN-15 $120 \mathrm{mg}$ and $240 \mathrm{mg}$ in adults with migraine with or without aura and to assess dose-response phenomena between $120 \mathrm{mg}$ and $240 \mathrm{mg}$.

\section{Methods}

\section{Ethical conduct}

Before any study-related activities were undertaken, the protocol, informed consent form, electronic diary, and other relevant study documents were approved by the institutional review board (IRB) of each study center. This study was conducted in compliance with the revised Guidelines of the World Medical Association Declaration of Helsinki (Brazil, 2013), guidelines of the International Council for Harmonisation of Technical Requirements for Pharmaceuticals for Human Use for current Good Clinical Practice, and the Code of Federal Regulations of the Food and Drug Administration, as well as the national drug and data protection laws and other applicable regulatory requirements. Patients provided written consent to participate in the study after having been informed about the nature and purpose of the study, participation/termination conditions, and risks and benefits of treatment.

\section{Study design}

This proof-of-concept study used a randomized, placebocontrolled, double-blind, 3-treatment, 6-sequence, 3-period crossover design. It was conducted at 6 study centers in the US. The protocol, informed consent form, screenshots of the electronic diary assessments, and other relevant study documents were approved by Quorum Review IRB (Seattle, WA, USA) before initiation of the study.

\section{Subjects}

Males and females, 18-65 years of age, satisfying International Classification of Headache Disorders, Second Edition (ICHD-2) criteria $^{11}$ for episodic migraine ( $\leq 14$ headachedays per month) with or without visual aura and who experienced 2 to 6 attacks of moderate or severe pain per month and were headache-free at least 48 hours between attacks were eligible to participate. Subjects were excluded if they had medication overuse headache (as defined by ICHD-2), a known hypersensitivity to celecoxib, or any medical condition that might confound the objectives of the study, or if they were taking botulinum toxin within 180 days of screening or unstable dosages of prophylactic medications for migraine within 30 days of screening. Subjects continued to take their usual migraine medication during the screening period.

\section{Treatments}

For this study, dose selection was based on PK modeling data from unpublished PK studies of DFN-15 prototypes. Study medications included oral formulations of DFN-15 $120 \mathrm{mg}, 240 \mathrm{mg}$, and placebo packaged together in a single carton with 2 identical amber-colored glass bottles containing $2.4 \mathrm{~mL}$ solution. Subjects were instructed to consume 1 bottle of DFN-15 solution and 1 bottle of placebo for the $120 \mathrm{mg}$ dose and 2 bottles of DFN-15 solution for the $240 \mathrm{mg}$ dose. For the placebo-treated attacks, subjects consumed 2 bottles of placebo. Placebo was matched to DFN-15 for taste.

For each treated migraine attack, subjects were instructed to use the study medication at the onset of moderate to severe headache pain (defined as patient headache pain rating of 2 or 3 on a scale of 0 to 3 ). In each of the 3 treatment periods, subjects treated 1 migraine attack at the onset of moderate to severe headache pain, but no later than 1 hour after the onset of moderate headache pain. Subjects were instructed to wait at least 4 days after a migraine attack before treating a new migraine attack with study medication.

\section{Assessments}

The primary efficacy end point was the proportion of patients who were pain-free at 2 hours after the initial dose of DFN-15 $120 \mathrm{mg}$ or $240 \mathrm{mg}$. Secondary efficacy variables included the following: headache intensity rating at 10, 15, 20, and 30 minutes and 1, 1.5, 2, 24, and 48 hours postdose; most 
bothersome symptom (MBS) among nausea, photophobia, and phonophobia; freedom from pain (time); symptoms (nausea, photophobia, and phonophobia) at 0, 2, 24, and 48 hours postdose; and rescue medication usage (date and time).

Subjects used an electronic diary to record pain intensity on a scale of 0 (no pain) to 3 (severe) at baseline; 10, 15, 20 , and 30 minutes postdose; and 1, 1.5, 2, 24, and 48 hours postdose, as well as the time at which they achieved freedom from pain. They were considered pain-free if they reported no pain (score of 0 ) at any time postdose. At baseline and 2, 24, and 48 hours postdose, subjects assessed the presence or absence of associated symptoms (nausea, photophobia, and phonophobia). Subjects were asked to identify their MBS from among associated symptoms for each of the 3 treated migraine attacks.

The PK variables were plasma concentration profile and systemic exposure levels of celecoxib in DFN-15 at $0.5(+0.5)$ and $2( \pm 0.5)$ hours postdose. Blood samples ( $2 \mathrm{~mL}$ each) were collected at these times to assess celecoxib plasma levels.

Safety was assessed on the basis of AE reports, study medication use, prior and concomitant medication use, clinical laboratory data (hematology, clinical chemistry, urinalysis, and serology), urine pregnancy tests, vital signs, electrocardiograms (ECGs), and physical examination. All AEs were coded using the Medical Dictionary for Regulatory Activities, version 17 or higher.

\section{Statistics}

Unless specified otherwise, CIs were 2-sided and statistical testing was performed using a significance (alpha) level of 0.05. Statistical analyses were conducted using the $\mathrm{SAS}^{\circledR}$ software package, version 9.1 .3 or higher. The efficacy population included all subjects who were randomized, took at least 1 dose of study medication, and had at least 1 postbaseline efficacy assessment. The safety population included all subjects who received at least 1 dose of doubleblind study medication. The time to freedom from headache postdose was analyzed using Kaplan-Meier survival estimation in the efficacy population. The corresponding $p$-values from log-rank test were computed for comparisons between treatment groups.

Based on the assumption that $12 \%$ of placebo-treated and $35 \%$ of DFN-15-treated subjects would be pain-free at 2 hours postdose, it was determined that a sample size of 60 subjects in each group would provide $80 \%$ power to detect this assumed difference. Since no controlled studies on celecoxib in migraine have been published, this effect size was estimated based on a randomized controlled trial in migraine comparing rofecoxib, ibuprofen, and placebo. ${ }^{12}$

\section{Results \\ Subjects}

Of 63 randomized subjects, 60 received at least 1 dose of study medication and had at least 1 postbaseline efficacy assessment, and 56 (89\%) took single doses of DFN-15 $120 \mathrm{mg}$ and $240 \mathrm{mg}$ and completed all 3 treatment periods (Figure 1). In total, 11\% of subjects (7/60) withdrew from study: $5.0 \%$ (3/60) withdrew consent, 3.3\% (2/60) had not treated 3 migraine attacks within 3 months of randomization, and $3.3 \%(2 / 60)$ were lost to follow-up.

The majority of subjects were female $(75.0 \%)$ and white $(86.7 \%)$. Mean age was 43.6 years, average weight was $80.61 \mathrm{~kg}$, and average body mass index was $28.48 \mathrm{~kg} / \mathrm{m}^{2}$, with most patients $(70.0 \%)$ having a body mass index less than $30 \mathrm{~kg} / \mathrm{m}^{2}$.

\section{Efficacy}

Both doses of DFN-15 showed better 2-hour pain-free response than placebo, with rates of $29.1 \%$ for $120 \mathrm{mg}, 26.1 \%$ for $240 \mathrm{mg}$, and $17.6 \%$ for placebo. There were no significant differences between the 2 DFN-15 doses and between DFN-15 and placebo at 2 hours postdose. In treatment period 1, 2-hour pain-free responses were $31.6 \%$ for DFN-15 $120 \mathrm{mg}, 13.3 \%$ for DFN-15 $240 \mathrm{mg}$, and $10.0 \%$ for placebo, with no significant differences observed (Figure 2).

\section{Most bothersome symptom}

Altogether, 85\% of subjects (51/60) identified an MBS. Photophobia was the most commonly reported MBS, but most subjects $(53 \% ; 27 / 51)$ showed variability in their identification of a symptom as most bothersome across attacks. At 2 hours postdose, the proportions of subjects who were free from their MBS were $50 \%$ for DFN- 15 $120 \mathrm{mg}, 39.5 \%$ for DFN-15 $240 \mathrm{mg}$, and $28.2 \%$ for placebo, with no significant differences between DFN-15 $120 \mathrm{mg}$

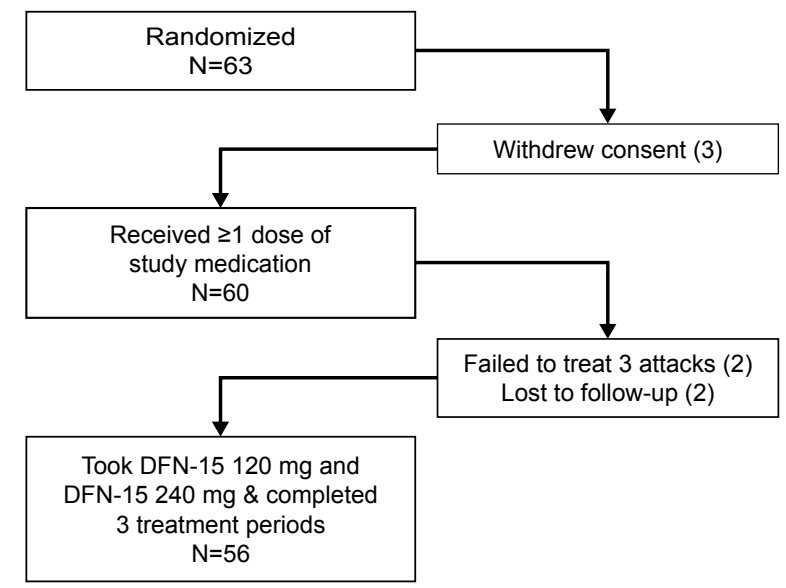

Figure I Disposition of subjects. 


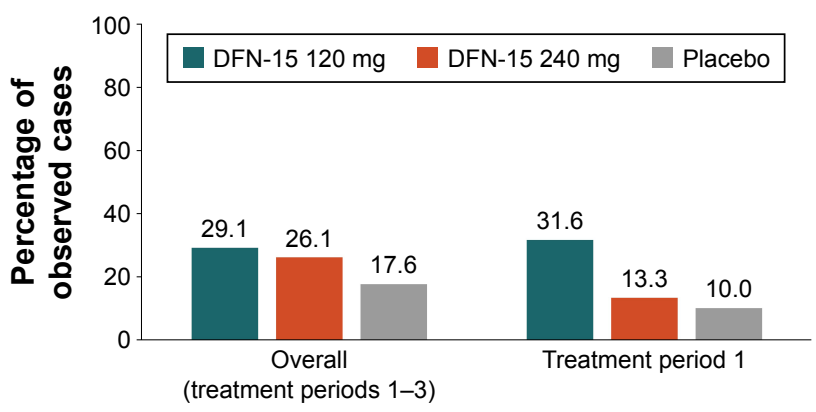

Figure 2 Freedom from pain 2 hours after treatment with DFN-I5 I 20 mg (overall and period I).

and $240 \mathrm{mg}$ and between DFN-15 and placebo. At 2 hours after treatment with DFN-15 $120 \mathrm{mg}$ in treatment period 1, $66.7 \%$ of subjects were free from nausea, $56.3 \%$ were free from photophobia, and $60 \%$ were free from phonophobia (Figure 3), and there was no significant difference between DFN-15 $120 \mathrm{mg}$ and placebo.

\section{Pharmacokinetics}

The present study yielded insufficient data for PK analysis and hence are not discussed here.

\section{Safety}

Overall, the doses of DFN-15 used in this study were safe and well tolerated (Table 1). A total of $26.7 \%$ of subjects (16/60) reported 37 treatment-emergent AEs (TEAEs) during the study, 13 of which were judged by the investigator to be related to study medication. The most commonly reported TEAEs were dysgeusia (reported 14 times by 6 subjects) and nausea (reported 6 times by 4 subjects). There were no serious AEs, and no AEs leading to study termination or death. Of the 16 subjects who reported TEAEs, 12 had mild events, 4 had moderate events, and none had severe events. There were no clinically meaningful changes from baseline for any clinical laboratory variable, vital sign, or ECG reading.

\section{Discussion}

This proof-of-concept study was undertaken to demonstrate the tolerability, safety, and efficacy of DFN-15 in the treatment

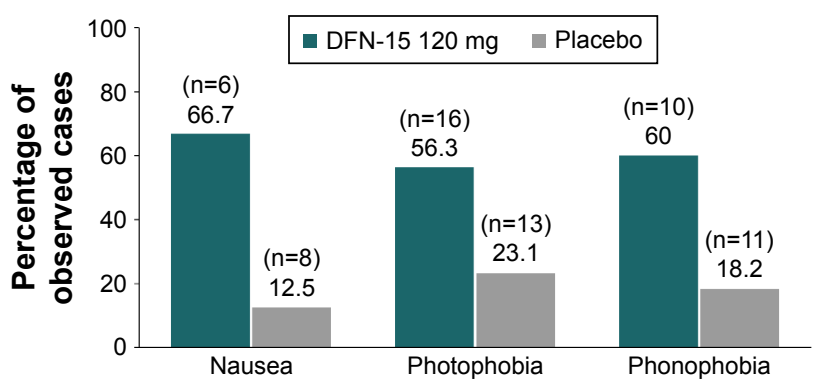

Figure 3 Freedom from most bothersome symptom 2 hours after treatment with DFN-I5 $120 \mathrm{mg}$ (period I). of acute migraine with or without aura. At 2 hours postdose, there was a numerical separation between DFN-15 and placebo. Since there was no dose-response relationship between DFN-15 120 and $240 \mathrm{mg}$, the $120 \mathrm{mg}$ dose is being further developed for the management of acute migraine attacks. The lack of significant difference from placebo may be due to the small sample size and an unexpectedly high placebo response, which itself may be related to the crossover design of the study. In treatment period 1 , the placebo response was consistent with other published studies, but in subsequent periods, the placebo rates were 2 to 3 times higher than anticipated. A larger, fully powered clinical trial, currently underway, will provide additional data on the efficacy and safety of DFN-15 $120 \mathrm{mg}$.

Due to the possibility of TEAEs,${ }^{13}$ migraine patients want treatments with minimal side effects. ${ }^{9}$ In this study, dysgeusia and nausea were the only AEs reported by more than 1 subject. Since there were no serious AEs, $75 \%$ of TEAEs were mild, and no subjects withdrew for safety reasons, the study results well support the use of DFN-15. Additional studies are needed to determine whether tolerability will be a barrier to care.

The heterogeneity of migraine attacks is well known. ${ }^{14}$ Its most prominent feature, headache, is usually (but not always) unilateral, throbbing, and ranging in intensity from mild to incapacitating, and the pain may be accompanied by nausea, vomiting, photophobia, and phonophobia. ${ }^{11,15}$ In addition, some migraineurs experience infrequent attacks $(<4$ per month) and little or no disability, while others have frequent attacks ( $\geq 15$ per month) and severe disability, ${ }^{16}$ and monthly variations in the frequency of attacks have been observed. ${ }^{17}$ This has led to the inclusion of patient-identified MBS as a potential co-primary end point in acute migraine clinical trials. ${ }^{18}$ Previous research has suggested that attacks tend to be characterized by high between-participant and smaller within-participant variability, ${ }^{19-21}$ but the variability of MBS across attacks within the same patient has not been studied. In this study, photophobia was most frequently rated as the MBS, although more than half of the subjects showed variability in identifying a symptom as most bothersome across attacks. Determining which aspects of migraine symptomatology are most bothersome to patients may help to refine drug selection and individualize treatment plans.

\section{Conclusion}

The $120 \mathrm{mg}$ and $240 \mathrm{mg}$ doses of DFN-15 showed differences from placebo for the 2-hour pain-free end point, but the differences were not statistically significant. No dose-response relationship was observed between DFN-15 
Table I Treatment-emergent adverse events after administration of DFN-I5 and placebo

\begin{tabular}{|c|c|c|c|c|c|}
\hline \multirow[t]{2}{*}{ Events } & \multirow{2}{*}{$\begin{array}{l}\text { Placebo } \\
(\mathrm{N}=53), \mathrm{n}(\%)\end{array}$} & \multicolumn{3}{|l|}{ DFN-I5 } & \multirow{2}{*}{$\begin{array}{l}\text { Overall } \\
(\mathrm{N}=60), \mathrm{n}(\%)\end{array}$} \\
\hline & & $\begin{array}{l}\text { I } 20 \mathrm{mg}(\mathrm{N}=5 \mathrm{I}) \\
\mathrm{n}(\%)\end{array}$ & $\begin{array}{l}240 \mathrm{mg}(\mathrm{N}=5 \mathrm{I}), \\
\mathrm{n}(\%)\end{array}$ & $\begin{array}{l}\text { Both }(N=59), \\
n(\%)\end{array}$ & \\
\hline Total & $9(17.0)$ & $8(15.7)$ & $9(17.6)$ & $12(20.3)$ & $16(26.7)$ \\
\hline Dysgeusia & $4(7.5)$ & $6(11.8)$ & $4(7.8)$ & $6(10.2)$ & $6(10.0)$ \\
\hline Nausea & $2(3.8)$ & I (2.0) & $3(5.9)$ & $3(5.1)$ & $4(6.7)$ \\
\hline Palpitation & $2(3.8)$ & 0 & 0 & 0 & $2(3.3)$ \\
\hline Somnolence & I (I.9) & 0 & 0 & 0 & $\mathrm{I}(\mathrm{I} .7)$ \\
\hline Abdominal pain & 0 & 0 & I (2.0) & I (I.7) & I (I.7) \\
\hline Diarrhea & 0 & 0 & I (2.0) & $\mathrm{I}(\mathrm{I} .7)$ & I (I.7) \\
\hline Vomiting & 0 & 0 & I (2.0) & I (I.7) & I (I.7) \\
\hline Viral gastroenteritis & 0 & 0 & I (2.0) & I (I.7) & I (I.7) \\
\hline Mononucleosis & 0 & I (2.0) & 0 & $\mathrm{I}(\mathrm{I} .7)$ & I (I.7) \\
\hline Peritonsillar abscess & 0 & 0 & I (2.0) & $\mathrm{I}(\mathrm{I} .7)$ & I (I.7) \\
\hline Dry eye & I (I.9) & I (2.0) & I (2.0) & I (I.7) & I (1.7) \\
\hline Insomnia & 0 & I (2.0) & 0 & $\mathrm{I}(\mathrm{I} .7)$ & I (I.7 \\
\hline Throat irritation & I (I.9) & $\mathrm{I}(2.0)$ & I (2.0) & $\mathrm{I}(\mathrm{I} .7)$ & I (I.7) \\
\hline Hot flush & 0 & 0 & I (2.0) & $\mathrm{I}(\mathrm{I} .7)$ & I (I.7) \\
\hline Hypertension & I (I.9) & 0 & 0 & 0 & I (I.7) \\
\hline
\end{tabular}

$120 \mathrm{mg}$ and $240 \mathrm{mg}$. There was substantial within-subject variability in MBS across attacks. DFN-15 $120 \mathrm{mg}$ is being further developed for the acute treatment of migraine attacks, and larger, parallel-group clinical trials will further clarify its efficacy.

\section{Acknowledgments}

Medical writing services were provided by Christopher Caiazza. This study was funded and sponsored by the Dr Reddy's Laboratories group of companies, manufacturer of oral liquid celecoxib.

\section{Disclosure}

SM and AB are employed by and own stock in Dr Reddy's Laboratories. The authors report no other conflicts of interest in this work.

\section{References}

1. Silberstein SD. Practice parameter: evidence-based guidelines for migraine headache (an evidence-based review): report of the Quality Standards Subcommittee of the American Academy of Neurology. Neurology. 2000;55(6):754-762.

2. Marmura MJ, Silberstein SD, Schwedt TJ. The acute treatment of migraine in adults: the american headache society evidence assessment of migraine pharmacotherapies. Headache. 2015;55(1):3-20.

3. Silverstein FE, Faich G, Goldstein JL, et al. Gastrointestinal toxicity with celecoxib vs nonsteroidal anti-inflammatory drugs for osteoarthritis and rheumatoid arthritis: the CLASS study: a randomized controlled trial. Celecoxib Long-term Arthritis Safety Study. JAMA. 2000;284(10): 1247-1255.

4. Moore RA, Derry S, Makinson GT, McQuay HJ. Tolerability and adverse events in clinical trials of celecoxib in osteoarthritis and rheumatoid arthritis: systematic review and meta-analysis of information from company clinical trial reports. Arthritis Res Ther. 2005;7(3): R644-R665.
5. Cryer B, LiC, SimonLS, Singh G, Stillman MJ, Berger MF. GI-REASONS: a novel 6-month, prospective, randomized, open-label, blinded endpoint (PROBE) trial. Am J Gastroenterol. 2013;108(3):392-400.

6. Celebrex (celecoxib capsule) [prescribing information]. New York: G.D. Searle LLC Division of Pfizer Inc; 2016. Available from: http:// labeling.pfizer.com/showlabeling.aspx?id=793. Accessed September 21, 2017.

7. Loo CY, Tan HJ, Teh HS, Raymond AA. Randomised, open label, controlled trial of celecoxib in the treatment of acute migraine. Singapore Med J. 2007;48(9):834-839.

8. Pal A, Shenoy S, Gautam A, et al. Pharmacokinetics of DFN-15, a novel oral solution of celecoxib, versus celecoxib 400-mg capsules: a randomized crossover study in fasting healthy volunteers. Clin Drug Investig. Epub 2017 Jul 26.

9. Lipton RB, Hamelsky SW, Dayno JM. What do patients with migraine want from acute migraine treatment? Headache. 2002;42 Suppl 1:3-9.

10. Burstein R, Collins B, Jakubowski M. Defeating migraine pain with triptans: a race against the development of cutaneous allodynia. Ann Neurol. 2004;55(1):19-26.

11. Headache Classification Subcommittee of the International Headache Society. The International Classification of Headache Disorders: 2nd edition. Cephalalgia. 2004;24 Suppl 1:9-160.

12. Saper J, Dahlof C, So Y, et al; Rofecoxib Protocol 162 Study Group. Rofecoxib in the acute treatment of migraine: a randomized controlled clinical trial. Headache. 2006;46(2):264-275.

13. Verrotti A, Parisi P, Agostinelli S, et al. Weight regain after discontinuation of topiramate treatment in patients with migraine: a prospective observational study. CNS Drugs. 2015;29(2):163-169.

14. Viana M, Sances G, Ghiotto N, et al. Variability of the characteristics of a migraine attack within patients. Cephalalgia. 2016;36(9):825-830.

15. Headache Classification Committee of the International Headache Society (IHS). The International Classification of Headache Disorders, 3rd edition (beta version). Cephalalgia. 2013;33(9):629-808.

16. Lipton RB, Stewart WF, Diamond S, Diamond ML, Reed M. Prevalence and burden of migraine in the United States: data from the American Migraine Study II. Headache. 2001;41(7):646-657.

17. Lipton RB, Serrano D, Adams AM, Buse DC, Scher AI. EHMTI-0169. Trajectories of headache days over one year (5 waves) in chronic and episodic migraineurs participating in the chronic migraine epidemiology and outcomes (cameo) study. J Headache Pain. 2014;15(Suppl 1):D4.

18. Food and Drug Administration. Guidance for industry migraine: developing drugs for acute treatment. Available from: https://www.fda. gov/downloads/Drugs/GuidanceComplianceRegulatoryInformation/ Guidances/UCM419465.pdf. Accessed September 21, 2017. 
19. Russell MB, Rasmussen BK, Brennum J, Iversen HK, Jensen RA, Olesen J. Presentation of a new instrument: the diagnostic headache diary. Cephalalgia. 1992;12(6):369-374.

20. Johannes CB, Linet MS, Stewart WF, Celentano DD, Lipton RB, Szklo M. Relationship of headache to phase of the menstrual cycle among young women: a daily diary study. Neurology. 1995;45(6):1076-1082.
21. Tfelt-Hansen P, Pascual J, Ramadan N, et al; International Headache Society Clinical Trials Subcommittee. Guidelines for controlled trials of drugs in migraine: third edition. A guide for investigators. Cephalalgia. 2012;32(1):6-38.

\section{Publish your work in this journal}

Neuropsychiatric Disease and Treatment is an international, peerreviewed journal of clinical therapeutics and pharmacology focusing on concise rapid reporting of clinical or pre-clinical studies on a range of neuropsychiatric and neurological disorders. This journal is indexed on PubMed Central, the 'PsycINFO' database and CAS, and is the official journal of The International Neuropsychiatric Association (INA). The manuscript management system is completely online and includes a very quick and fair peer-review system, which is all easy to use. Visit http://www.dovepress.com/testimonials.php to read real quotes from published authors.

\footnotetext{
Submit your manuscript here: http://www.dovepress.com/neuropsychiatric-disease-and-treatment-journal
} 